\title{
The effects of lesions in the frontal or posterior association cortex of rats on maze III
}

\author{
ROGER K. THOMAS and VENDER KNOWLES WEIR \\ University of Georgia, Athens, Georgia 30602
}

\begin{abstract}
The present work (a) examined an earlier suggestion that Lashley's law of equipotentiality received questionable support from the principal data used in its formulation and (b) compared the effects of lesions in the areas believed to represent frontal (MF) and parietal association cortex in the rat. Another frontal area (FP), often said to be an association area, was lesioned, and sham-operated controls were included. Only the $\mathrm{MF}$ and parietal lesions led to postoperative retention deficits. It was suggested that Lashley's law of equipotentiality, even in the limited context that he presented it, should no longer be reported uncritically. Further discussion considered the involvement of MF and parietal neocortex in spatially related behaviors and the need to focus on MF rather than FP cortex as the frontal association area.
\end{abstract}

The principles of mass function and equipotentiality as Lashley (1929) conceived of them might seem to be outdated issues of concern to neuropsychologists. However, the validity of these principles as well as some of the more important data used in Lashley's formulation of them, namely retention on Maze III, continues to be reported with minimal or no criticism in contemporary secondary sources in physiological psychology (e.g., Kimble, 1973; Leukel, 1972; Milner, 1970; Schwartz, 1973).

While in many respects the principles of mass function and equipotentiality have been weakened by subsequent data and interpretations, nevertheless, they seem to have been regarded as particularly valid in certain contexts. For example, Hebb (1963) attempted to dispel misconceptions regarding Lashley's position on these principles but also noted: "In general, his opinion was that mass action and equipotentiality are most evident in complex problems-in Maze III, for example, as compared with Maze I" (p. xiii). More recently, Chow (1967) stated: "While some recent reports take exception to these principles, Lashley's conclusions still hold for the effects of cortical lesions on alley-maze performance of rats" (p. 707).

Based on a reanalysis of Lashley's Maze III retention data (1929, pp. 92-93) and noting that there were insufficient acquisition data on which to perform comparable reanalyses, Thomas (1970) suggested that an area within the parietal cortex played a significant role (i.e., nonequipotential) in Maze III retention.

Further, it is suggested here that this parietal area is contained within the posterior association cortex of the rat. This suggestion may require documentation as there is disagreement in the literature regarding the existence of posterior association cortex in the rat. For example, some sources state or imply its nonexistence (Barnett,

Requests for reprints should go to Roger K. Thomas, Department of Psychology, University of Georgia, Athens, Georgia 30602 .
1963; Penfield, 1966; Thompson, 1967) while others appear to take its existence for granted (Ain, Lubar, Moon, \& Kulug, 1969; Skinner, 1971; Woolsey, 1958). Craigie's Neuroanatomy of the Rat (Zeman \& Innes, 1963) has no mention of posterior association cortex.

In primates, posterior association cortex is frequently described in terms of the projection fields of the lateral posterior thalamic nucleus and the pulvinar (e.g., Brodal, 1969; Pribram, 1958; Truex \& Carpenter, 1969). It is on the basis of thalamic projections that the existence of posterior association cortex in the rat is suggested here. In the rat, the relevant nucleus appears to be the lateral thalamic. Gurdjian (1927), Clark (1973), and Lashley (1941) described the lateral thalamic nucleus as having two parts, pars principalis and pars posterior. All agreed that pars posterior is the forerunner of the pulvinar seen in higher mammalian forms. Clark emphasized the relationship between pars principalis and the parietal association cortex. Without elaborating, except to invite comparisons with the report by Diamond and Hall (1969), it is suggested that the projection field of pars posterior may be considered to be temporal association cortex. Together, the projection fields of pars principalis and pars posterior of the lateral nucleus in the rat are suggested to describe posterior association cortex.

Using retrograde degeneration, Lashley (1941) provided estimates of the projection fields of pars principalis (his Figure 15) and pars posterior (his Figure 18; this figure has a slight error in the legend which may confuse the reader momentarily; obviously, the reference to Figure 15 should have been to Figure 17). It was Lashley's rats (1929) with lesions in the projection field of pars principalis which provided the data that, according to Thomas (1970), raised questions for the validity of mass function and equipotentiality.

Frontal association cortex, particularly in carnivores and primates, has been described in terms of the 
projection fields of portions of the dorsomedial thalamic nucleus (e.g., Akert, 1964). Leonard (1969) has shown the two neocortical areas in the rat which receive mediodorsal thalamic projections. One of these areas is on the medial surface of the anterior cerebrum and the other is on the dorsal lip of the rhinal sulcus. Leonard cautiously suggested that the mediodorsal projection areas in the rat may be, in part, homologous to primate prefrontal cortex.

There was reason to suggest that rats with the medial frontal (MF) lesions might show retention deficits on Maze III. Delayed alternation deficits are commonly seen in primates with frontal association cortex lesions, and Maze III has elements of delayed alternation in that the rat must go R L R L R from startbox to goalbox with delays of the time required to traverse the distances between choice points (16 in.). The present study, then, included rats with lesions of the MF or parietal cortices. Sham-operated and frontal neocortical pole lesion (FP) controls were also included, the latter because Lashley (1929) did not find deficits on Maze III following FP lesions of the sizes intended here.

\section{METHOD}

\section{Subjects}

Twenty-two male hooded rats (Blue-Spruce Farms, Inc., Altamont, N. Y.), 90 days old at the beginning of the experiment, were used. All rats received the same behavioral training. However, based on error scores in the preoperative retention test, and as they met criterion, the animals were assigned to receive either parietal $(N=6), M F(N=6)$, or FP $(N=5)$ lesions or sham operations $(N=5)$ prior to the postoperative retention test. The assignments were made to keep the groups as evenly matched as possible, based on preoperative retention.

\section{Surgical Procedures}

Following an intraperitoneal injection of Equithesin (.25 cc/100 g of body weight), the dorsal hair on the cranium was clipped, and a midline incision of the scalp was made. The parietal, medial frontal (MF), or frontopolar (FP) cortices were exposed by drilling the skull with a trephine. Locating a trephine with an outside diameter of $3.5 \mathrm{~mm}$, bilaterally, $1 \mathrm{~mm}$ from the saggital suture and $1 \mathrm{~mm}$ posterior to the coronal suture and suctioning the area beneath the opening yielded the desired size and position for the parietal lesions. The same trephine was used bilaterally at a position about $1 \mathrm{~mm}$ from the saggital suture and $1 \mathrm{~mm}$ anterior to the coronal suture to achieve the desired FP lesions. A trephine with an outside diameter of $5.5 \mathrm{~mm}$ was centered on the midline with the posterior edge even with the coronal suture to make the opening for the MF lesions. Following aspiration of the neocortex, the scalp was sutured and powdered with a tetracycline medication. Sham operations consisted of proceeding to the point of drilling through the skull. However, at this point, the incision was sutured, the cranium dusted with tetracycline, and the animal was returned to his home cage to recover.

\section{Anatomical}

At the end of the experiment, the rats were sacrificed with an overdose of Equithesin. After surgical anesthesia had been reached, a thoracic incision was made, the heart was exposed and intracardial perfusion of $50 \mathrm{cc}$ of $.85 \%$ saline followed by $50 \mathrm{cc}$ of $10 \%$ formalin was done. The brain was then placed in $10 \%$ formalin for a minimum of 2 days. The brain was photographed on continuous tone Polaroid projection film, and then it was embedded in celloidin, sectioned at 40 micrometers and stained (every fifth section) with thionin or by the Weil method for myelin, alternately. The projection slide of the whole brain was focused on a Lashley brain diagram, adjusted so the image and the diagram were in a 1:1 relationship, and the lesion boundaries were traced on the diagram. Percentages of cerebral cortical destruction were determined for the FP and parietal lesions with the dot grid method (Thomas \& Peacock, 1965). MF lesion percentages would be meaningless in the present context as Lashley did not include the medial cortical surfaces in arriving at his denominator, and comparisons with Lashley are desired in the present work for the parietal and FP lesions. To calculate a denominator which included the medial walls to measure the MF lesions would yield measures that are not comparable to the others. To measure the MF lesions with a denominator that does not include much of the lesioned area would also be inappropriate.

\section{Feeding Schedules}

The rats were placed on 48-h food deprivation prior to preliminary training and $24-\mathrm{h}$ food deprivation prior to the resumption of any stage of training. Otherwise, the animals were fed 12-15 g Purina Laboratory Chow each day in the home cage following completion of the day's trials. During those periods when the animals were not being trained (e.g., preoperative retention interval in Maze III and postoperative recovery periods), they also received $12-15 \mathrm{~g}$ per day. Water was available ad lib except during trials.

\section{Training}

The procedures used with Maze III training and testing were replications of those used by Lashley (1929) except where there were procedures that were not fully described and for which procedures had to be designed. Generally, these were concerned with preliminary training. Room illumination was provided by a 25 -W bulb which was mounted on the bottom and in the center of the table holding the apparatus.

In pretraining, a straight runway $(10.2 \times 10.2 \times 304.8 \mathrm{~cm})$, painted gray, and with a wire mesh top, was used. Sliding doors, $30.5 \mathrm{~cm}$ from either end defined a startbox and a goalbox. The animal was first placed in the goalbox fives times daily until he learned to eat two food pellets $(.045 \mathrm{~g}$, P. J. Noyes Co.) placed there each time. He was then given five trials per day to run from the startbox to the goalbox for two food pellets until he ran unhesitatingly (within $10 \mathrm{sec}$ ) on three consecutive trials.

On the day following completion of preliminary training, the rats were adapted to feeding in the goalbox of Maze III by placing them three times in the goalbox with two food pellets available each time. Also on this day, the rat was given one trial to run from the startbox to the goalbox. This trial was terminated when the animal entered the goalbox and ate the food. Thereafter, each rat was given five trials per day until 10 consecutive errorless trials were recorded. Trials were limited to $5 \mathrm{~min}$. Errors were recorded if the animal entered a cul-de-sac to the extent of his thorax or if he retraced the maze. Those animals which failed to enter the goalbox within $5 \mathrm{~min}$ were placed there and allowed to eat the food.

Ten days after criterion was met, retraining to the same criterion began. This was the preoperative retention test. Ten days postoperatively, the rats were again retrained to criterion as before. This was the postoperative retention test.

\section{Maze III}

\section{RESULTS}

Behavioral results. The rats with parietal or MF lesions showed significantly more postoperative errors 


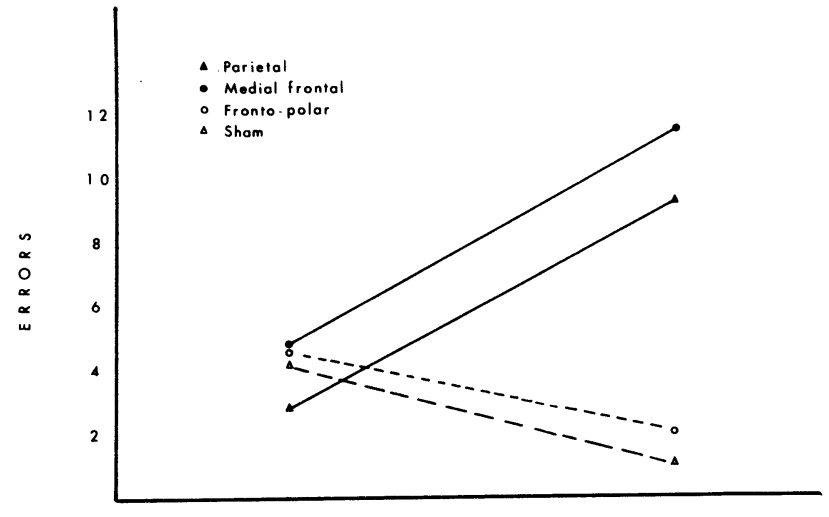

Preoperative

RETENTION TESTS

Figure 1. Mean errors on pre- and postoperative tests for retention of Lashley's Maze III as functions of parietal, medial frontal, and frontopolar lesions and sham operations.

compared with preoperative retention errors or compared with the FP lesion group or the sham-operated group. The FP and sham-operated groups showed a slight but nonsignificant reduction in errors postoperatively (Figure 1). These conclusions were based on the results of an analysis of variance for a two-factor experiment with repeated measures on one factor and with appropriate adjustments for unequal ns. This analysis revealed a significant lesion effect $(\mathrm{F}=4.95 ; \mathrm{df}=3,18 ; \mathrm{p}<.05)$
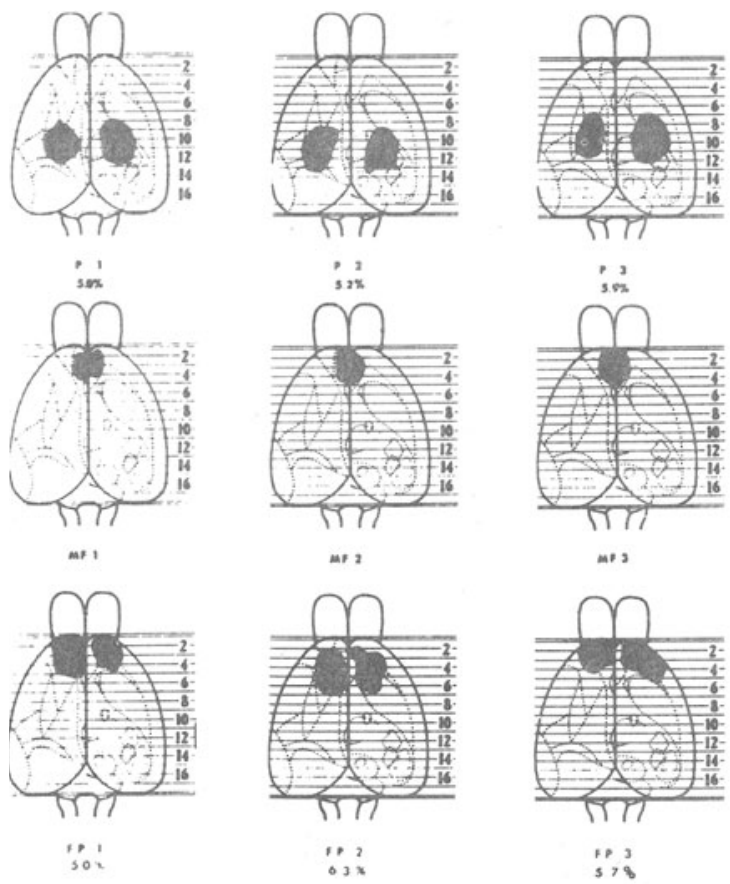

and a significant Lesions by Tests interaction $(\mathrm{F}=3.29$; $\mathrm{df}=3,18 ; \mathrm{p}<.05)$. Analysis of the simple main effects showed that the groups differed significantly postoperatively $(\mathrm{F}=6.25 ; \mathrm{df}=3,18 ; \mathrm{p}<.01)$ but not preoperatively $(\mathrm{F}<1)$. Additionally, the parietal lesion group differed significantly on the pre- and postoperative retention tests $(\mathrm{F}=4.64 ; \mathrm{df}=1,18$; $\mathrm{p}<.05)$ as did the MF lesion group $(\mathrm{F}=4.89 ; \mathrm{df}=1,18$; $\mathrm{p}<.05$ ), but the FP lesion group and the sham-operated group did not differ significantly on the two retention tests. The difference in performance between the parietal and the MF lesion groups seen in Figure 1 was not significant preoperatively, and examination of the individual scores suggests that it was not significant postoperatively.

Anatomical results. Tracings of the lesions on Lashley brain diagrams may be seen in Figure 2. All parietal lesion subjects showed some degree of damage to the corpus callosum, but generally this was slight. Five of six MF subjects showed some damage to the corpus callosum. Figure 3 shows tracings of coronal sections of the brains of the rats with MF lesions.

\section{DISCUSSION}

The results confirmed the view (Thomas, 1970) that lesions from $5 \%$ to $10 \%$ of the rat's cerebral cortex, when located in the parietal area, will interfere significantly with retention on Maze III. Lesions of comparable magnitude but located in the FP area did not affect Maze III retention compared to either
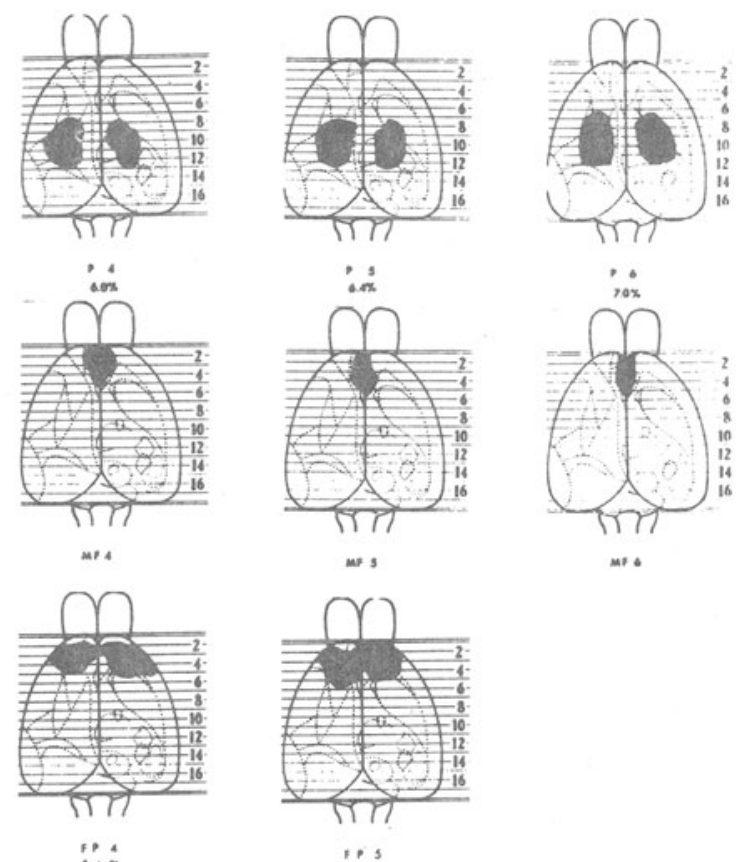

ms

mo \&

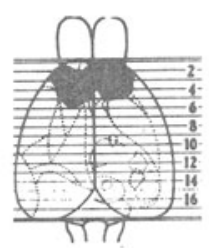

$\because s$

Figure 2. Lashley brain diagrams illustrating the extent of dorsal neocortical damage in the parietal (P), medial frontal (MF), and frontopolar (FP) lesion groups. 

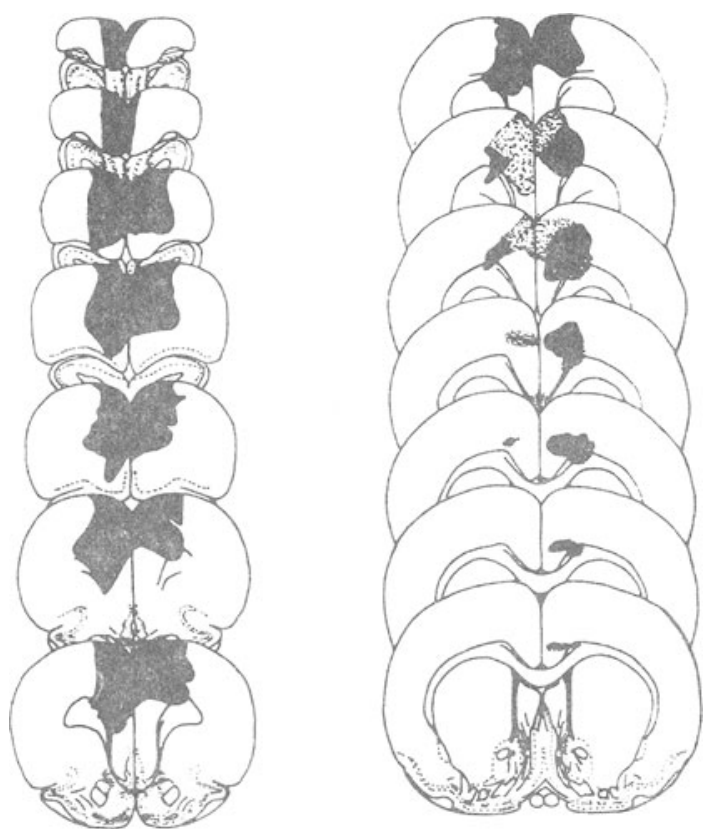

Figure 3. A representative medial frontal lesion. (The animal, MF 2, was selected randomly. Diagrams of the brain sections were derived from the most rostral 14 coronal sections in Konig \& Klippel, 1963.)

preoperative retention measures or data from the sham-operated controls. Furthermore, and as anticipated, lesions of the MF cortex in rats resulted in significant postoperative retention deficits on Maze III. The data then, suggest significant involvement of the parietal and MF cortices of the rat in the retention of the ability to perform Maze III.

The deficits, as estimated from error scores, are relatively small following the parietal and MF lesions of the present work compared to deficits seen in Lashley's (1929) animals with lesions greater than 15\%. Since approximately 45 years intervened between Lashley's work and the present study, it may be appropriate to comment on the findings between the two studies where meaningful comparisons may be made. A mean of 3.8 errors was seen in Lashley's preoperative retention test data compared to our preoperative retention mean of 4.1. Lashley's (1929, p. 92) first nine rats, viewed here as lesion controls, with lesions ranging from $4.5 \%$ to $8.7 \%$ (including some in the parietal area but none there as much as $5 \%$; none in the MF area) had a mean of 1.4 errors postoperatively compared to our combined FP lesion controls' and sham-operated controls' mean of 1.5. Therefore, despite the many differences which must have existed between Lashley's classic study and the experiment reported here, there appears to be sufficient similarity to discuss them together where they bear on the laws of mass action and equipotentiality. In light of Thomas' (1970) earlier suggestion based on his reanalysis of Lashley's Maze III retention data and the empirical confirmation of that suggestion shown here, it would appear to be inappropriate to continue to report uncritically Lashley's laws of mass action and equipotentiality in the context of the classic 1929 report.

That the frontal and parietal association cortices interfere with Maze III performance is consistent with other studies suggesting the involvement of these areas in spatial performance. In the rat, Divac (1971), in one of the few studies to date investigating the behavioral effects of lesions in the frontal projection area of the mediodorsal thalamic nucleus (Leonard, 1969), reported deficits in spatial reversal learning following MF but not FP lesions, and it is pertinent to note that Krechevsky's (1935) "spatial hypothesis" area coincides closely with the area of parietal lesions in the present work. Also relevant are three studies showing deficits on the "closed field test of rat intelligence" with lesions essentially within the parietal area lesioned in the present work (Ain et al., 1969; Forgays, 1952; Thomas, 1966). This test consists of a series of mazes.

It is not suggested, however, that the frontal and posterior association cortices are equivalent with regard to spatial behavior. In primates, while it has been shown that both frontal and posterior lesions may affect spatial performances, some bases for differentiating the spatial deficits have been reported (e.g., Iversen, 1973; Pohl, 1973). For example, Pohl suggests that deficits following frontal lesions are related to the animal's inability to use cues based on body position and that deficits following parietal lesions are the result of an inability to use external cues. Maze III appears to have both types of cues in that an animal might learn simply to alternate (bodily cues?) or to detect and avoid the cul-de-sacs (external cues?) or, more likely, the rat uses both cues. The slight but significant deficits seen in the present work may represent a breakdown in the MF or parietal lesioned rats' ability to use both sets of cues as the normal rat might. Obviously, further study is necessary to establish a dissociation of spatial deficits similar to that seen in the primate.

The frontal pole of the rat was generally considered to be the homolog, if there is one, of frontal association cortex in carnivores and primates (see Leonard, 1969; Divac, 1971). However, this view has been changing since Leonard's (1969) anatomical study suggested that the MF cortex and a dorsal rhinal sulcul area were the recipients of mediodorsal thalamic projections. The present work adds to others which have shown dissociation of the behavioral effects of FP and MF lesions (Albert \& Bignami, 1968; Divac, 1971). Such findings may point to the need for further research on the MF area in the context of its being frontal association cortex in the rat.

\section{REFERENCES}

Ain, B. R., Lubar, J. F., Moon, R. D., \& Kulug, B. M. Effect of septal and neocortical damage on complex maze learning. Physiology and Behavior, 1969, 4, 235-238. 
Akert, K. Comparative anatomy of frontal cortex and thalamofrontal connections. In J. M. Warren and K. Akert (Eds.), The frontal granular cortex and behavior. New York: McGraw-Hill, 1964.

Albert, M., \& Bignami, G. Effects of frontal median cortical and caudate lesions on two-way avoidance learning by rats. Physiology and Behavior, 1968, 3, 141-147.

Barnett, S. A., The rat. Chicago: Aldine, 1963

Brodal, A. Neurological anatomy (2nd ed.). New York: Oxford University Press, 1969.

Chow, $K$. L. Effects of ablation. In G. C. Quarton, T. Melnechuk, and F. O. Schmitt (Eds.): The neurosciences. New York: Rockefeller University Press, 1967.

Clark, W. E. L. An experimental study of thalamic connections in the rat. Philosophical Transactions, Royal Society of London, 1932, 222B, 1-28.

Diamond, I. T., \& Hall, W. C. Evolution of neocortex. Science, 1969, 164, 251-262.

Divac, I. Frontal lobe system and spatial reversal in the rat. Neuropsy chologia, 1971, 9, 175-183.

Forgays, D. G. Reversible disturbances of function in rats following cortical insult. Journal of Comparative and Physiological Psychology, 1952, 45, 216-225.

Gurdjian, E. S. The diencephalon of the albino rat. Journal of Comparative Neurology, 1927, 43, 1-114.

Hebb, D. O. Introduction to Dover edition. In K. S. Lashley: Brain mechanisms and intelligence. New York: Dover, 1963.

Iversen, S. D. Brain lesions and memory in animals. In J. A Deutsch (Ed.), The physiological basis of memory. New York: Academic Press, 1973.

Kimble, D. P. Psychology as a biological science. Pacific Palisades, California: Goodyear, 1973.

König, J. F. R., \& Klippel, R. A. The rat brain. Baltimore: Williams and Wilkins, 1963.

Krechevsky, I. Brain mechanisms and "hypotheses." Journal of Comparative Psychology, 1935, 19, 425-468.

Lashley, $\mathrm{K}$. S. Brain mechanisms and intelligence. Chicago: University of Chicago Press, 1929.

Lashley, K. S. Thalamo-cortical connections of the rat's brain. Journal of Comparative Neurology, 1941, 75, 67-121.

Leonard, C. M. The prefrontal cortex of the rat. I. Cortical projection of the mediodorsal nucleus. II. Efferent connections. Brain research, 1969, 12, 321-343.
Leukel, F. Introduction to physiological psychology Saint Louis Mosby, 1972.

Milner, P. M. Physiological psyshology New York: Holt Rinehart, and Winston, 1970.

Penfield, W. Speech, perception and the cortex. In J. C. Eccles (Ed.), Brain and conscious experience. New York: Springer-Verlag, 1966.

Pohl, W. Dissocation of spatial discrimination deficits followin frontal and parietal lesions in monkeys. Journal of Comparative and Physiological Psychology, 1973, 82, 227-239.

Pribram, $\dot{K}$. Comparative neurology and the evolution of behavior. In G. G. Simpson and A. Roe (Eds.), Behavior and evolution 1958.

Skinner, J. E. Neuroscience: A laboratory manual. Philadelphia: W. B. Saunders, 1971.

Schwartz, M. Physiological psychology. New York: Appleton-Century-Crofts, 1973.

Thomas, R. K. Immediate and subsequent effects of brain damage in rats. Journal of Comparative and $P$ hysiological Psychology, 1966, 62, 472-475.

Thomas, R. K. Mass function and equipotentiality: A reanlay sis of Lashley's retention data. Psy chological Reports, 1970, 27, 899-902.

Thomas, R. K., \& Peacock, L. J. A method for measuring brain lesions. Psychonomic Science, 1965, 3, 184

Thompson, R. F. Foundations of physiological psychology. New York: Harper and Row, 1967.

Truex, R. C., \& Carpenter, M. B. Human neuroanatomy. Baltimore: William and Wilkins, 1969.

Woolsey, C. N. Organization of somatic sensory and motor areas of the cerebral cortex. In $\mathbf{H}$. F. Harlow and $C$. $N$. Woolsey (Eds.), Biological and biochemical bases of behavior. Madison: University of Wisconsin Press, 1958.

Zeman, W., \& Innes, J.'R. M. Craigie's neuroanatomy of the rat. New York: Academic Press, 1963.

(Received for publication September 25, 1974; revision accepted December 31, 1974.) 